Int. J. Electrochem. Sci., 14 (2019) $6133-6146$

International Journal of

ELECTROCHEMICAL

SCIENCE

www.electrochemsci.org

\title{
Passivation Behavior and Corrosion Resistance of 904L Austenitic Stainless Steels in Static Seawater
}

\author{
Dan Yang ${ }^{1,2,3,5}$, Yanliang Huang ${ }^{1,3,5, *}$, Peng Peng ${ }^{4}$, Xiangju Liu ${ }^{1,2,3,5}$, Binbin Zhang ${ }^{1,3,5}$ \\ ${ }^{1}$ CAS Key Laboratory of Marine Environmental Corrosion and Bio-fouling, Institute of Oceanology, \\ Chinese Academy of Sciences, Qingdao 266071, China \\ ${ }^{2}$ University of Chinese Academy of Sciences, Beijing 100049, China \\ ${ }^{3}$ Open Studio for Marine Corrosion and Protection, Qingdao National Laboratory for Marine Science \\ and Technology, Qingdao 266237, China \\ ${ }^{4}$ CSG Power Generation Co., Ltd, Guangzhou 511400, China \\ ${ }^{5}$ Center for Ocean Mega-Science, Chinese Academy of Sciences, Qingdao 266237, China \\ *E-mail: hyl@qdio.ac.cn
}

doi: $10.20964 / 2019.07 .14$

Received: 4 February 2019 / Accepted: 18 April 2019 / Published: 10 June 2019

The passive properties of 904L ASS in a seawater pumped storage system were studied by polarization curves, and performed by EIS and Mott-Schottky analysis. The results confirmed that the passive film formed on 904L ASS performs as n-type and p-type semiconductors at different potential ranges. The passive film that formed at $0.2 \mathrm{~V}$ vs. SCE has the lowest densities of donors and acceptors. The effect of temperature on the corrosion behavior of the 904L austenitic stainless steel in static seawater, which simulated the static period of seawater pumped storage systems, was determined by Tafel polarization and EIS. Based on the results of the electrochemical measurements, the corrosion rate of 904L ASS was found to increase with rising temperatures. 904L ASS has excellent corrosion resistance in static seawater. Due to its corrosion resistance, $904 \mathrm{~L}$ ASS can be used to fabricate key structures of seawater pumped storage power systems.

Keywords: Seawater pumped storage system; 904L ASS; Passive film; Corrosion resistance;

Temperature; Electrochemical measurements

\section{FULL TEXT}

(C) 2019 The Authors. Published by ESG (www.electrochemsci.org). This article is an open access article distributed under the terms and conditions of the Creative Commons Attribution license (http://creativecommons.org/licenses/by/4.0/). 